\title{
INCIDENCE AND FACTORS ASSOCIATED WITH PERICARDIAL EFFUSION AFTER CARDIAC VALVE SURGERY
}

\author{
Eduardo Ferreira Martins ${ }^{1}$, Adriano Heemann Pereira Neto', \\ Lucas Danielli ${ }^{1}$, Lisandra Almeida Nunes ${ }^{1}$, Maria Vitória França do Amaral ${ }^{2}$, \\ Paulo Kalil2 ${ }^{2}$, Orlando Wender², Murilo Foppa², \\ Ângela Barreto Santiago Santos ${ }^{2}$
}

Clin Biomed Res. 2017;37(1):18-24

1 Universidade Federal do Rio Grande do Sul (UFRGS). Porto Alegre (RS), Brazil.

2 Cardiology Division, Hospital de Clínicas de Porto Alegre (HCPA). Porto Alegre (RS), Brazil.

Corresponding author:

Ângela Barreto Santiago Santos angelabssantos@yahoo.com.br Hospital de Clínicas de Porto Alegre (HCPA)

Ramiro Barcelos, 2350.

90035-903, Porto Alegre, RS, Brazil.

\section{ABSTRACT}

Introduction: Pericardial effusion (PE) is a postoperative complication of cardiac valve surgery, related to early hospital readmissions and death. We aimed to describe its incidence and to identify predictive factors of moderate-to-severe PE in a contemporary cohort.

Methods: We retrospectively reviewed medical records of all consecutive patients submitted to cardiac valve surgery in a tertiary teaching hospital from January 2012 to July 2014 , where echocardiography was routinely performed before patient discharge. Moderate-to-severe PE was defined as $\geq 10 \mathrm{~mm}$ of thickness, or signs of cardiac tamponade on echocardiography. Additional clinical and perioperative data were extracted from medical records using a standardized protocol.

Results: Of 353 patients, 335 underwent a predischarge echocardiography. From these, 27 patients (8\%; mean age: 62 years; standard deviation 12 years; $70 \%$ male) had moderate-to-severe PE. These patients had a higher prevalence of previous stroke ( $22 \%$ vs. $8 \% ; p=0.009$ ) and oral anticoagulation (international normalized ratio $>2$ ) prior to the surgery (11 vs. $2 \% ; P=0.002)$. In patients with moderate-to-severe $P E$, surgeries had longer ischemia $(p<0.001)$ and cardiopulmonary bypass $(p<0.001)$ times, and the prevalence of postoperative atrial fibrillation was higher (56\% vs. $32 \%$; $p=0.011$ ) than in patients with absent or small PE. Hospital mortality was also higher $(15 \%$ vs. $3 \% ; p=0.002)$ in patients with moderate-to-severe PE.

Conclusions: Eight percent of patients submitted to cardiac valve surgery developed moderate-to-severe PE. Moreover, PE was associated with pre- and post-surgery conditions likely related to the coagulation state, though a cause-effect relationship could not be inferred. Noteworthy, this condition was associated with higher in-hospital morbidity and mortality.

Keywords: Adult; pericardium; postoperative care

Pericardial effusion (PE) is a postoperative complication of open-heart surgery. It may lead to cardiac tamponade, early readmissions and reinterventions, and increased mortality rates ${ }^{1}$. The reported incidence of postoperative PE varies from $1 \%$ to $77 \% \%^{2,3}$ depending on the type of surgery, clinical characteristics, and the criteria used for identification and quantification. Cardiac valve surgery is one of the procedures most related to the development of $\mathrm{PE}^{3}$. A higher risk for postoperative PE has been associated with higher body surface area, pulmonary thromboembolism, hypertension, renal failure, immunosuppression, emergency surgery status, type of cardiac operation other than coronary artery bypass grafting, and prolonged cardiopulmonary bypass ${ }^{4,5}$. As a consequence, identifying predictors for the development of $\mathrm{PE}$ after cardiac valve surgery may help to prevent or reduce its occurrence. 
In this study, we aimed to determine the incidence of moderate-to-severe PE after cardiac valve surgery and the risk factors associated with this condition in a tertiary teaching hospital.

\section{METHODS}

In this cross-sectional analysis, we studied patients submitted to cardiac valve surgery who underwent predischarge echocardiographic examination between January 2012 and July 2014, in the Hospital de Clínicas de Porto Alegre. The institutional review board approved the study and waived written informed consent.

Data were extracted from medical records and the Department of Cardiac Surgery administrative registry using a standardized form. We collected preoperative data about previous comorbidities, medication use, blood tests, imaging exams, and surgical indication; intraoperative data about surgery time and surgical technique; and postoperative data about thoracic drainage, medication use, atrial fibrillation, stroke, severe bleeding, reinterventions, readmissions, and mortality.

Of the 353 identified patients, 335 were included in this study (16 patients died and two patients did not undergo a predischarge echocardiography). Patients were categorized into two groups: moderate-to-severe $P E$ and absent or small PE (figure 1). Moderate-to-severe $P E$ was defined as $\geq 10 \mathrm{~mm}$ of thickness ${ }^{6}$, or signs of cardiac tamponade on echocardiography. Patients who did not match these criteria were classified as absent of small PE.

\section{Statistical Analysis}

Data were presented as mean and standard deviation or median and interquartile range (IQR) (continuous data) or as count and proportion

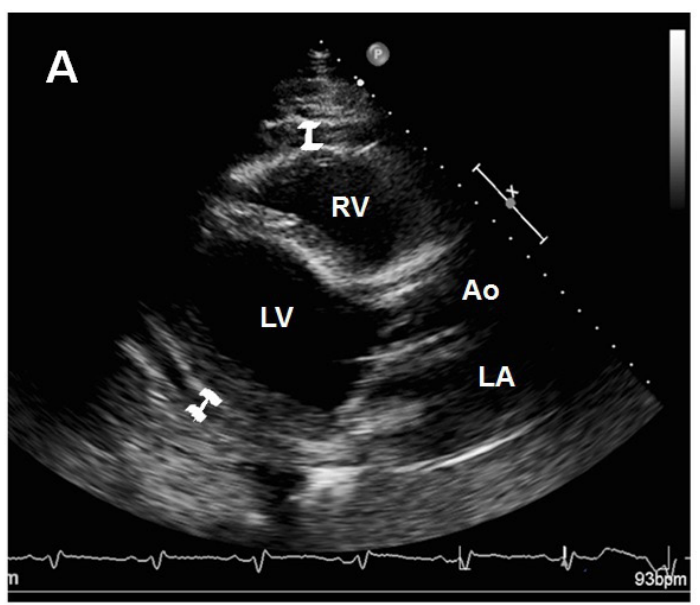

(categorical and ordinal data). Continuous variables were compared using the independent-samples $t$ test and categorical variables were compared using the chi-square test. After univariate screening, multivariable linear regression was used to adjust for selected clinically and statistically significant pre-and intraoperative covariates (age, sex, history of stroke, preoperative international normalized ratio (INR) levels, and surgery time).

All statistical analyses were performed with PASW 18.0 (SPSS Inc, Chicago). All tests were two-sided and $p$-values of $<0.05$ were considered statistically significant.

\section{RESULTS}

\section{Patients}

The majority of echocardiographic examinations were conducted up to 6 days of after surgery (median: 6.0 days; IQR: $5.0-7.0)$. From January 2012 to July 2014, moderate-to-severe PE occurred in 27 (8\%) of 335 patients submitted to cardiac valve surgery (mean age: 62; standard deviation 12 years; $70 \%$ male). Five of those presented with echocardiographic signs of increased intrapericardial pressure or clinical cardiac tamponade. Patients with moderate-to-severe PE had more history of stroke and asthma than absent or small PE patients, but were similar to those with respect to other preoperative clinical and echocardiographic characteristics (table 1). The group with moderate-to-severe PE had lower hemoglobin and hematocrit levels, higher INR, and a higher prevalence of INR greater than 2 compared to the absent or small PE group (table 2). The association between moderate-to-severe PE and preoperative INR levels remained statistically significant after adjustments.

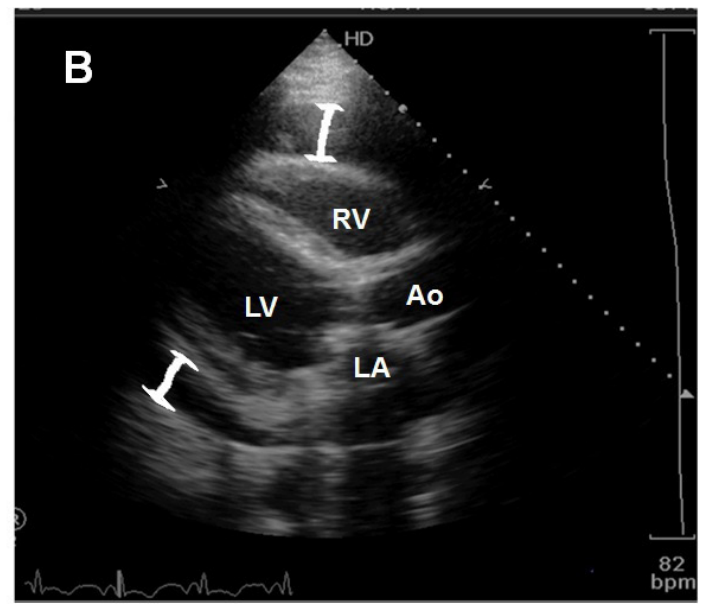

Figure 1: (A) Small pericardial effusion $(<10 \mathrm{~mm}$ ) and (B) Large pericardial effusion ( $\geq 10 \mathrm{~mm}$ ) on the postoperative echocardiographic examination. RV: right ventricule, LV: left ventricule, Ao: Aorta, LA: left atrium. 
Table 1: Preoperative characteristics.

\begin{tabular}{|c|c|c|c|}
\hline & $\begin{array}{c}\text { Moderate-to-Severe PE } \\
(\mathrm{n}=27)\end{array}$ & $\begin{array}{c}\text { Absent or Small PE } \\
(n=308)\end{array}$ & $p$ value \\
\hline Age, years & $62 \pm 12$ & $61 \pm 14$ & 0.108 \\
\hline Male & $19(70)$ & $156(51)$ & 0.049 \\
\hline $\mathrm{BMI}, \mathrm{kg} / \mathrm{m}^{2}$ & $27.3 \pm 5.1$ & $27.6 \pm 5.1$ & 0.629 \\
\hline Body surface area, $\mathrm{m}^{2}$ & $1.85 \pm 0.23$ & $1.79 \pm 0.22$ & 0.800 \\
\hline Skin color, white & $27(100)$ & $290(94)$ & 0.434 \\
\hline Diabetes & $7(26)$ & $67(22)$ & 0.616 \\
\hline Dyslipidemia & $6(22)$ & $48(16)$ & 0.368 \\
\hline Hypertension & $16(59)$ & $214(70)$ & 0.272 \\
\hline Heart Failure & $13(48)$ & $173(56)$ & 0.421 \\
\hline Ischemic Heart Disease & $6(22)$ & $81(26)$ & 0.643 \\
\hline Stroke & $6(22)$ & $23(8)$ & 0.009 \\
\hline Immunosuppression & $1(4)$ & $4(1)$ & 0.323 \\
\hline Chronic Renal Disease & $2(7)$ & $24(8)$ & 0.943 \\
\hline Asthma & $3(11)$ & $8(3)$ & 0.017 \\
\hline COPD & $3(11)$ & $13(4)$ & 0.107 \\
\hline Atrial fibrillation & & & 0.586 \\
\hline Paroxysmal & $2(7)$ & $11(4)$ & \\
\hline Persistent/Permanent & $4(15)$ & $41(13)$ & \\
\hline Previous Cardiac Surgery & $3(11)$ & $29(9)$ & 0.774 \\
\hline \multicolumn{4}{|l|}{ Preoperative medications } \\
\hline Antiplatelet agents* & $9(33)$ & $110(36)$ & 0.804 \\
\hline Oral anticoagulants** & $5(19)$ & $29(9)$ & 0.133 \\
\hline Nitrate & $0(0)$ & $23(8)$ & 0.141 \\
\hline Antihypertensive drugs ${ }^{* * *}$ & $22(82)$ & $248(81)$ & 0.904 \\
\hline Digitalis & $4(15)$ & $39(13)$ & 0.748 \\
\hline Antiarrhythmic agents & $1(4)$ & $17(6)$ & 0.688 \\
\hline \multicolumn{4}{|l|}{ Echocardiographic findings } \\
\hline Aortic diameter, cm & $3.3 \pm 0.6$ & $3.4 \pm 0.6$ & 0.870 \\
\hline Left atrium diameter, $\mathrm{cm}$ & $4.9 \pm 0.8$ & $4.6 \pm 0.8$ & 0.648 \\
\hline LV diastolic diameter, $\mathrm{cm}$ & $5.7 \pm 1.2$ & $5.4 \pm 1.0$ & 0.696 \\
\hline LV systolic diameter, cm & $3.7 \pm 1.0$ & $3.6 \pm 1.0$ & 0.606 \\
\hline Septum thickness, $\mathrm{cm}$ & $1.1 \pm 0.2$ & $1.1 \pm 0.3$ & 0.113 \\
\hline LV posterior wall, cm & $1.0 \pm 0.2$ & $1.0 \pm 0.2$ & 0.217 \\
\hline Ejection fraction, \% & $62 \pm 14$ & $61 \pm 12$ & 0.824 \\
\hline $\mathrm{RV}$ diameter, cm & $2.4 \pm 0.4$ & $2.3 \pm 0.5$ & 0.660 \\
\hline
\end{tabular}

BMI: Body Mass Index; COPD: Chronic Obstructive Pulmonary Disease; LV: Left Ventricle; PE: Pericardial Effusion; RV: Right Ventricle. ${ }^{*}$ Antiplatelet agents: Aspirin or clopidogrel. ${ }^{* *}$ Anticoagulants: Warfarin or new oral anticoagulants. ${ }^{* * *}$ Antihypertensive drugs: beta-blockers, angiotensin converting enzyme inhibitors, angiotensin receptor blockers, calcium channel blockers, diuretics. Data are presented as mean \pm SD or $\mathrm{n}$ (percentage).

Table 2: Preoperative laboratory data.

\begin{tabular}{lccc}
\hline & $\begin{array}{c}\text { Moderate-to-Severe PE } \\
(\mathbf{n = 2 7})\end{array}$ & $\begin{array}{c}\text { Absent or Small PE } \\
(\mathbf{n = 3 0 8})\end{array}$ & p value \\
\hline INR & $1.27 \pm 0.75$ & $1.05 \pm 0.19$ & $<0.001$ \\
INR $>2$ & $3(11)$ & $7(2)$ & 0.002 \\
Platelets, $\times 10^{3} \mathrm{mg} / \mathrm{dL}$ & $212 \pm 60$ & $216 \pm 71$ & 0.673 \\
Hematocrit, $\%$ & $37.2 \pm 7.5$ & $38.1 \pm 5.3$ & 0.038 \\
Hemoglobin, $\mathrm{mg} / \mathrm{dL}$ & $12.4 \pm 2.7$ & $12.8 \pm 2.0$ & 0.027 \\
Creatinine, $\mathrm{mg} / \mathrm{dL}$ & $1.3 \pm 1.5$ & $1.2 \pm 1.0$ & 0.091 \\
\hline
\end{tabular}

INR: International Normalized Ratio; PE: Pericardial Effusion. Data are presented as mean \pm SD and $\mathrm{n}$ (percentage). 


\section{Surgery}

The most performed surgery was aortic valve replacement (70\%) and the most common indication for the procedure was aortic valve stenosis $(55 \%)$. Ninety-three (28\%) patients were submitted to multiple procedures (for example, aortic valve replacement and coronary artery bypass graft surgery) during the surgery. Patients with moderate-to-severe PE had longer surgeries, as well as longer periods of ischemia and cardiopulmonary bypass (table 3 ).
Surgical status (elective or urgent/emergent surgery) did not differ between groups, nor did the proportion of patients submitted to multiple procedures.

\section{Postoperative Parameters}

Postoperative data are presented in Table 4. Patients with moderate-to-severe PE had longer periods with thoracic drain than patients with absent or small PE, with a mean difference of 5.3 hours (33.6 hours vs. 28.3 hours; $p=0.001)$, though the total drained volume

Table 3: Surgical parameters.

\begin{tabular}{lccc}
\hline & $\begin{array}{c}\text { Moderate-to-Severe PE } \\
(\mathbf{n = 2 7})\end{array}$ & $\begin{array}{c}\text { Absent or Small PE } \\
(\mathbf{n = 3 0 8})\end{array}$ & p value \\
\hline Surgical status & & & 0.363 \\
Elective & $24(89)$ & $288(93)$ & \\
Urgent/Emergent & $3(11)$ & $20(7)$ & \\
Multiple indications & $6(22)$ & $97(32)$ & 0.317 \\
Multiple procedures & $6(22)$ & $87(28)$ & 0.503 \\
Total surgery time, min & $183 \pm 62$ & $159 \pm 50$ & 0.041 \\
Ischemia time, min & $71 \pm 30$ & $58 \pm 22$ & $<0.001$ \\
CPB time, min & $88 \pm 35$ & $74 \pm 26$ & $<0.001$ \\
\hline
\end{tabular}

CPB: Cardiopulmonary Bypass. Data are presented as mean \pm SD or $n$ (percentage).

Table 4: Postoperative parameters.

\begin{tabular}{|c|c|c|c|}
\hline & $\begin{array}{c}\text { Moderate-to-Severe PE } \\
(\mathrm{n}=27)\end{array}$ & $\begin{array}{c}\text { Absent or Small PE } \\
(n=308)\end{array}$ & $p$ value \\
\hline Days with drain & $1.4 \pm 0.9$ & $1.18 \pm 0.5$ & 0.001 \\
\hline Atrial fibrillation & $15(56)$ & $97(32)$ & 0.011 \\
\hline New onset atrial fibrillation & $10(37)$ & $62(20)$ & 0.038 \\
\hline \multicolumn{4}{|l|}{ Medications } \\
\hline Anticoagulants* & $19(70)$ & $179(58)$ & 0.214 \\
\hline Antiplatelet agents ${ }^{* *}$ & $7(26)$ & $168(55)$ & 0.004 \\
\hline NSAIDs & $6(22)$ & $34(11)$ & 0.086 \\
\hline Colchicine & $8(30)$ & $11(4)$ & $<0.001$ \\
\hline Corticosteroids & $5(19)$ & $9(3)$ & $<0.001$ \\
\hline \multicolumn{4}{|l|}{ Echocardiographic findings } \\
\hline Aortic diameter, cm & $3.4 \pm 0.5$ & $3.4 \pm 0.6$ & 0.143 \\
\hline Left atrium diameter, $\mathrm{cm}$ & $4.9 \pm 0.7$ & $4,5 \pm 0.8$ & 0.551 \\
\hline LV diastolic diameter, $\mathrm{cm}$ & $5.1 \pm 0.6$ & $5.1 \pm 0.9$ & 0.155 \\
\hline LV systolic diameter, cm & $3.6 \pm 0.8$ & $3.5 \pm 0.9$ & 0.290 \\
\hline Septum thickness, cm & $1.1 \pm 0.2$ & $1.1 \pm 0.3$ & 0.113 \\
\hline LV posterior wall, cm & $1.1 \pm 0.2$ & $1.1 \pm 0.2$ & 0.307 \\
\hline Ejection fraction,\% & $58 \pm 12$ & $58 \pm 13$ & 0.842 \\
\hline RV diameter, cm & $2.3 \pm 0.3$ & $2.3 \pm 0.5$ & 0.300 \\
\hline Reoperation for bleeding & $4(15)$ & $14(5)$ & 0.023 \\
\hline Reoperation for other causes & $3(11)$ & $7(2)$ & 0.010 \\
\hline Days of hospitalization & $24 \pm 17$ & $15 \pm 13$ & 0.007 \\
\hline Deaths & $4(15)$ & $9(3)$ & 0.002 \\
\hline
\end{tabular}

${ }^{*}$ Anticoagulants = Warfarin or Heparin or Enoxaparin. ${ }^{*}$ Antiplatelet agents: Aspirin or Clopidogrel. NAIDs: Nonsteroidal anti-inflammatory drugs; LV: Left ventricle; RV: Right Ventricle. Data are presented as mean \pm SD or $n$ (percentage). 
did not differ. Moderate-to-severe PE patients had a lower postoperative prescription of antiplatelet agents, i.e. aspirin or clopidogrel $(p=0.004)$, and a similar use of anticoagulants compared to patients with absent or small PE. Additionally, Moderate-to-severe PE patients had a higher use of colchicine $(p<0.001)$ and corticosteroids $(p<0.001)$ due to suspected postpericardiotomy syndrome. The time to start the postoperative medications, including oral anticoagulant therapy, and postoperative blood test results were similar between the groups. There was also no difference in postoperative echocardiographic measures. The moderate-to-severe PE group had more reintervention for bleeding $(15 \%$ vs. $5 \% ; p=0.023)$ and for other causes ( $11 \%$ vs. $2 \%$; $p=0.01$ ), and three patients developed clinical cardiac tamponade. This group also had more episodes of postoperative atrial fibrillation (56\% vs. $32 \%$, $p=0,011)$. The hospitalization was longer in patients with moderate-to-severe PE compared to those with absent or small PE $(24 \pm 17$ days vs. $15 \pm 13$ days; $p=0.007$ ). The rate of postoperative deaths was significantly higher in patients from the group with moderate-to-severe PE (15\% vs. $3 \% ; p=0.002)$.

\section{DISCUSSION}

In this study, the incidence of moderate-to-severe $\mathrm{PE}$ following cardiac valve surgery was $8 \%$. We found that patients who develop moderate-to-severe PE had a higher prevalence of previous stroke, higher levels of preoperative INR, longer surgery times, and higher prevalence of new and recurrent postoperative atrial fibrillation than patients with absent or small $\mathrm{PE}$. Moreover, the group with moderate-to-severe PE underwent more reinterventions (for bleeding and for other causes) and had a greater number of deaths.

The high variability of the reported PE incidence after cardiac surgery is related to the different definitions for this condition $3,7,8$. Our study used only echocardiographic parameters to define PE, while others used clinical presentation and echocardiographic data $^{7}$; however, our incidence of PE is in the lower range of published incidence rates. This may be attributed to the fact that echocardiograms were systematically performed in all patients, regardless of symptoms.

\section{Preoperative Considerations}

We identified that history of stroke was a risk factor for the development of moderate-to-severe PE. This association could be attributed to a higher use of antiplatelet agents and anticoagulants aiming at secondary prevention. Although not statistically significant, the prevalence of anticoagulated patients was almost twice as high in the group with moderate-to-severe $\mathrm{PE}$, which is likely to be clinically relevant. Besides that, higher levels of preoperative INR was the most important factor associated with moderate-to-severe PE. Some studies have found association between the previous use of immunosuppressive therapy and the development of postoperative $\mathrm{PE}^{4,9}$, although we only had two patients taking these drugs. The protective association between history of previous cardiac surgery and PE reported in other studies ${ }^{4,10,11}$ was not present in our analysis.

\section{Intraoperative Considerations}

Patients with moderate-to-severe PE were more likely to have longer surgeries, with longer periods of ischemia and cardiopulmonary bypass. This finding has already demonstrated to be an important risk factor for $\mathrm{PE}^{3,12}$, which may be related to changes in coagulation parameters during these periods. We did not find differences in the types of cardiac valve replacement and the type of prosthesis (mechanic or biologic). Some authors have shown that aortic root and aortic aneurysm surgery are independent risk factors for the development of significant postoperative PE due to prolonged cardiopulmonary bypass and extensive dissection of the heart and the aorta ${ }^{4,13,14}$. In this study, we analyzed the combination of aortic root with cardiac valve replacement, but we did not find a higher risk to develop moderate-to-severe PE in this subgroup.

\section{Postoperative Considerations}

Patients with moderate-to-severe PE presented higher rate of postoperative atrial fibrillation than absent or small PE patients, similarly to the results described by lkäheimo et al. ${ }^{8}$ Arrhythmia can be a marker of higher risk of adverse outcomes in these patients ${ }^{15,16}$ which may have mediated a higher incidence of clinical endpoints regardless the presence of PE.

Aspirin reduces the risk of death and ischemic complications $^{12}$ after coronary artery bypass grafting, but it is associated with a higher risk of postoperative $\mathrm{PE}^{3,17}$. In our analysis, patients with moderate-to-severe PE used less aspirin and had a similar use of anticoagulants compared to absent or small PE patients. This finding reinforces the safety of early postoperative aspirin administration regarding PE risk.

The efficacy of anticoagulation after cardiac valve surgery depends on a delicate balance between the risk of thromboembolic events and risk of bleeding, and the appropriate time to start these drugs is not clear $^{18,19}$. Although PE is one of the main concerns regarding proper anticoagulation initiation, our data 
are not enough to suggest a specific recommendation in this aspect.

The association between the time of chest tube removal and PE is a controversial topic. Most of our patients had their chest drainage removed on the second postoperative day. Some authors showed that there is no difference between early ( $<24$ hours) and late ( $\geq 24$ hours) chest tube removal ${ }^{20,21}$. Chest tube withdrawal delay would increase the risk of infection and would cause more discomfort to patients ${ }^{22,23}$, but its early removal could predispose to the development of $\mathrm{PE}^{24}$. In our study, we did not find significant difference between the groups with respect to time of chest tube removal.

The development of moderate-to-severe PE was related to higher risk of reinterventions and death. The causes of deaths were related to cardiogenic shock and septic shock. Only patients from the group of moderate-to-severe PE presented cardiac tamponade. Although, Kuvin et al. ${ }^{3}$ reported a high rate of cardiac tamponade after postoperative moderate-to-severe PE (74\%), we found a rate of $11 \%$ among patients with moderate-to-severe PE. This discrepancy may be due to differences in the definition of cardiac tamponade.

\section{Study Limitations}

Some limitations of this analysis should be noted. Although most of our results are consistent with what was reported in the literature, our sample of moderate-to-severe PE patients was small and our study was based on a retrospective analysis of medical records limited to one study center. We analyzed only cardiac valve surgeries, since all these patients should have undergone an echocardiographic examination before hospital discharge as a routine of our service. Additionally, we lack information about the high risk group, since we excluded patients who died before performing the hospital discharge routine.

\section{CONCLUSION}

In our study, the incidence of moderate-to-severe $P E$ in patients submitted to cardiac valve surgery is not low, but still in the lower range of previous reports. This condition may be associated with preoperative coagulation state, and also with prolonged surgery and postoperative higher morbidity and mortality. Identifying risk factors associated with moderate-to-severe PE may help to better prevent or reduce the occurrence of this condition.

\section{REFERENCES}

1. Izadi Amoli A, Bozorgi A, HajHossein Talasaz A, Salehi Omran A, Mortazavi $\mathrm{SH}$, Jalali A, et al. Efficacy of colchicine versus placebo for the treatment of pericardial effusion after open-heart surgery: a randomized, placebo-controlled trial. Am Heart J. 2015;170:1195-201.

2. Stevenson LW, Child JS, Laks H, Kern L. Incidence and significance of early pericardial effusions after cardiac surgery. Am J Cardiol. 1984;54(7):848-51. PMid:6486036. http://dx.doi.org/10.1016/S00029149(84)80219-2.

3. Kuvin JT, Harati NA, Pandian NG, Bojar RM, Khabbaz KR. Postoperative cardiac tamponade in the modern surgical era. Ann Thorac Surg. 2002;74(4):1148-53. PMid:12400760. http://dx.doi.org/10.1016/S00034975(02)03837-7.

4. Ashikhmina EA, Schaff HV, Sinak LJ, Li Z, Dearani JA, Suri RM, et al. Pericardial effusion after cardiac surgery: risk factors, patient profiles, and contemporary management. Ann Thorac Surg. 2010;89(1):1128. PMid:20103217. http://dx.doi. org/10.1016/j.athoracsur.2009.09.026
5. Pepi M, Muratori M, Barbier $\mathrm{P}$, Doria E, Arena V, Berti M, et al. Pericardial effusion after cardiac surgery: incidence, site, size, and haemodynamic consequences. Br Heart J. 1994;72(4):327-31. PMid:7833189. http://dx.doi. org/10.1136/hrt.72.4.327.

6. Klein AF, Abbara S, Agler D, Appleton CP, Asher CR, Hoit $B$, et al. American Society of Echocardiography Clinical Recommendations for Multimodality Cardiovascular Imaging of Patients with Pericardial Disease. J Am Soc Echocardiogr. 2013;26(9):965-1012.

7. Tsang TS, Barnes E, Hayes SN, Freeman WK, Dearani JA, Butter SL, et al. Clinical and echocardiographic characteristics of significant pericardial effusion following cardiothoracic surgery and outcomes of echo-guided pericardiocentesis for management. Chest. 1999;116(2):322-31. PMid:10453858. http://dx.doi. org/10.1378/chest.116.2.322.

8. Cheung EW, Ho SA, Tang KK, Chau AK, Chiu CS, Cheung YF. Pericardial effusion after open heart surgery for congenital heart disease. Heart. 2003;89(7):780-3. PMid:12807856. http://dx.doi.org/10.1136/ heart.89.7.780.

9. Vandenberg BF, Mohanty PK, Craddock KJ, Barnhat G, Hanrahan J, Szentpetery S, et al. Clinical significance of pericardial effusion after heart transplantation. $J$ Heart Transplant. 1988;7(2):128-34. PMid:3284984.

10. Hauptman P, Couper G, Aranki S, Kartashov A, Mudge GJ JR, Loh E. Pericardial effusions after cardiac transplantation. J Am Coll Cardiol. 1994;23(7):1625-9. PMid:8195523. http://dx.doi.org/10.1016/07351097(94)90666-1.

11. Quin JA, Tauriainen MP, Huber LM, McIntire DD, Kaiser PA, Ring WS, et al. Predictors of pericardial effusion after orthotopic heart transplantation. $J$ Thorac Cardiovasc Surg. 2002;124(5):97983. PMid:12407382. http://dx.doi. org/10.1067/mtc.2002.124387.

12. Ball JB, Morrison WL. Experience with cardiac tamponade following open heart surgery. Heart Vessels. 
1996;11(1):39-43. PMid:9119804. http://dx.doi.org/10.1007/BF01744598.

13. Alkhulaifi AM, Speechly-Dick ME, Swanton RH, Pattinson CW, Pugsley WB. The incidence of significant pericardial effusion and tamponade following major aortic root surgery. $J$ Cardiovasc Surg (Torino). 1996;37(4):385-9. PMid:8698784.

14. Eryilmaz S, Emiroglu O, Eyileten Z, Akar R, Yazicioglu L, Tasoz R, et al. Effect of posterior pericardial drainage on the incidence of pericardial effusion after ascending aortic surgery. J Thorac Cardiovasc Surg. 2006;132(1):27-31. PMid:16798298. http://dx.doi.org/10.1016/j. jtcvs.2006.01.049.

15. Thorén E, Hellgren L, Granath F, Hörte L, Ståhle E. Postoperative atrial fibrillation predicts cause-specific late mortality after coronary surgery. Scand Cardiovasc J. 2014;48(2):71-8 PMid:24533700. http://dx.doi.org/10.3 109/14017431.2014.880793.

16. Bramer S, van Straten A, Soliman Hamad MA, Berreklouw E, Martens EJ, Maessen JG. The impact of new-onset postoperative atrial fibrillation on mortality after coronary artery bypass grafting. Ann Thorac Surg. 2010;90(2):4439. PMid:20667326. http://dx.doi. org/10.1016/j.athoracsur.2010.03.083.
17. Malouf JF, Alam S, Gharzeddine $W$, Stefadouros MA. The role of anticoagulation in the development of pericardial effusion and late tamponade after cardiac surgery. Eur Heart J. 1993;14(11):14517. PMid:8299624. http://dx.doi. org/10.1093/eurheartj/14.11.1451.

18. Yanagawa B, Whitlock RP, Verma S, Gersh BJ. Anticoagulation for prosthetic heart valves: unresolved questions requiring answers. Curr Opin Cardiol. 2016;31(2):176-82. PMid:26731290. http://dx.doi.org/10.1097/ HCO.0000000000000259.

19. Massel D, Little S. Antiplatelet and anticoagulation for patients with prosthetic heart valves. Cochrane Database Syst Rev. 2013;9(7):CD003464. PMid:23839768.

20. Mirmohammad-Sadeghi $S$, Etesampour A, Gharipour M, Shariat Z, Nilforoush P, Saeidi M, et al. Early chest tube removal after coronary artery bypass graft surgery. $N$ Am J Med Sci. 2009;1(7):333-7. PMid:22666720.

21. Gercekoglu H, Aydin NB, Dagdeviren B, Ozkul V, Sener T, Demirtas M, et al. Effect of timing of chest tube removal on development of pericardial effusion following cardiac surgery. J Card Surg.
2003;18(3):217-24. PMid:12809395. http://dx.doi.org/10.1046/j.15408191.2003.02020.x.

22. Mueller XM, Tinguely F, Tevaearai HT, Ravussin P, Stumpe F, von Segesser LK. Impact of duration of chest tube drainage on pain after cardiac surgery. Eur J Cardiothorac Surg. 2000;18(5):570-4. PMid:11053819. http://dx.doi.org/10.1016/S10107940(00)00515-7.

23. Oldfield MM, El-Masri MM, FoxWasylyshyn SM. Examining the association between chest-tuberelated factors and the risk of developing healthcare-associated infections in the ICU of a community hospital: a retrospective case-control study. Intensive Crit Care Nurs. 2009;25(1):38-44. PMid:18693112. http://dx.doi.org/10.1016/j. iccn.2008.07.001.

24. Andreasen JJ, Sørensen GV, Abrahamsen ER, Hansen-Nord E, Bundgaard K, Bendtsen MD, et al Early chest tube removal following cardiac surgery is associated with pleural and/or pericardial effusions requiring invasive treatment. Eur $J$ Cardiothorac Surg. 2016;49(1):28892. PMid:25661079. http://dx.doi. org/10.1093/ejcts/ezv005.

Received: Nov 07, 2016 Accepted: Jan 12, 2017 